\title{
NASIONALISME DALAM ISLAM
}

\author{
Azman \\ Fakultas Syariah dan Hukum Universitas Islam Negeri (UIN) Alauddin Makassar
}

\begin{abstract}
Nationalism is the longing for its homeland (nationalism of longing), or the necessity of fighting to liberate the homeland from imprealism (nationalism of honor and freedom), or strengthening its intercommunity bonds (nationalism), or liberating other countries (liberation nationalism), these things are something that is fitrah and acceptable and even some are regarded as obligations. On the contrary, if nationalism is meant to divide the Muslims into groups so that they become hostile to each other, then people are exploited to fulfill personal ambition (party politics), then it is certainly fake nationalism that will not give any benefit. The main nationalism is nationalism that opens up to the role of revelation. Devotion to the nation and state is worship. But he denounces narrow and oppressed nationalism, because then the excessive love of the nation will give rise to the pride and pride of the nation.
\end{abstract}

\section{Keywords:}

State, Nationalism, Islam

\begin{abstract}
Abstrak
Nasionalisme adalah kerinduan/keberpihakan terhadap tanah airnya (nasionalisme kerinduan), atau keharusan berjuang membebaskan tanah air dari imprealisme (nasionalisme kehormatan dan kebebasan), atau memperkuat ikatan kekeluargaan antar-masyarakatnya (nasionalisme kemasyarakatan), atau membebaskan negeri-negeri lain (nasionalisme pembebasan), hal-hal tersebut merupakan sesuatu yang fitrah dan dapat diterima bahkan ada yang dianggap sebagai kewajiban. Sebaliknya apabila nasionalisme itu dimaksudkan untuk memilah umat islam menjadi kelompok-kelompok sehingga mereka menjadi berseteru satu sama lain, kemudian umat dieksploitasi untuk memenuhi ambisi pribadi (nasionalisme kepartaian), maka itu pasti nasionalisme palsuan yang tidak akan memberi manfaat sedikitpun. Nasionalisme yang utama adalah nasionalisme yang membuka diri terhadap peranan wahyu. Pengabdian kepada bangsa dan negara merupakan ibadah. Namun ia mengecam nasionalisme sempit dan berkelbihan, sebab dengan demikian cinta bangsa yang berlebihan akan menimbulkan kecongkakan dan kesombongan bangsa.
\end{abstract}

Kata Kunci:

Negara, Nasionalisme, Islam 


\section{A. PENDAHULUAN}

\section{Latar Belakang}

$\mathrm{N}$

egara bangsa atau nation state sebagai fakta politik Indonesia sekarang merupakan hasil perjuangan para pemimpin terdahulu. Negara bangsa yang merupakan perkembangan termodern mulai muncul pertama kali di dunia Barat pada abad 18. Kehadiran negara bangsa merupakan pengganti negara dinasti yang mulai pudar semenjak revolusi Perancis dan revolusi Industri di Inggris, Italia, Jerman dan negara-negara Eropa lainnya. Perkembangan ini dimungkinkan oleh munculnya paham kebangsaan atau nasionalisme yang mengikat kesatuan dan solidaritas masyarakat yang tergabungdalam kesadaran itu. Dengan demikian, antara negara bangsa dan nasionalisme merupakan elemen yang saling menunjang, dimana satuan geografis tertentu sekaligus menjadi batasan bangsa. Nasionalisme menjadi faktor penentu yang mengikat semangat serta loyalitas untuk mewujudkan cita bersama mendirikan sebuah negara bangsa. Landasan nasionalisme dibangun oleh kesadaran sejarah, cinta tanah air dan cita politiknya. $^{1}$

Cinta tanah air merupakan fitrah manusia. Cinta tanah air ibaratkan cinta pada diri sendiridan jiwanya, meskipun apa adanya, bahkan sering kali bangga akan keindahan dan kebagusan dirinya. Dasarnya menurut Mas mashur adalah:

"Tiap jiwa mempunyai roh, dan tiap-tiap roh itu bertanah air pada jiwanya, tidak ubahnya sebagai saya yang bertanah air pada jiwa dan badan saya. Dan kewajiban bagi saya untuk menjaganya, memeliharanya, mencintainya kepada tanah air yang bertempat pada jiwa saya itu."2

Dalam hal ini sering juga kita mendengar ungkapan" cinta tanah air sebagian dari iman". Apapun yang terkait dengan tanah air kita, sedikitnya perhatikan kita akan terarah untuk itu. Keinginan untuk senantiasa kembali atau pulang ke tanah air atau kampung sendiri sering muncul ketika kita berada jauh darinya. Karena ada dasar cinta (dengan segala aspeknya) yang mengikat dan memanggil.

Wawasan kebangsaan bagi rakyat indonesia, utamanyaumat islam, memiliki peran penting yang sangat strategis dalam menjaga ketahanan bangsa dalam kerangka Negara Kesatuan Republik Indonesia. ${ }^{3}$

Keberagaman budaya dan agama dapat menjadi sumber perpecahan di masyarakat yang tidak mustahil munculnya separatisme. Namun, karena bangsa indonesia merupakan bangsa yang toleran, religius, dan menyadari bahwa keberagaman merupakan realitas sosial dan sebuah sunnatullah (ketentuan), maka kekhawatiran itu dapat berubah menjadi sebuah optimisme untuk membangun persatuan dan kebersamaan yang sebenarnya. Dengan modal keberagaman

\footnotetext{
${ }^{1}$ Dwi Purwoko dkk, Negara Islam, Percikan Pemikiran: H. Agus Salim, KH. Mas Manshur, Mohammad Natsir, KH. Hasyim Asyari, (Depok: Permata Artika Kreasi, 2001), hlm.37

${ }^{2}$ Dwi Purwoko dkk, Negara Islam, Percikan Pemikiran: H. Agus Salim, KH. Mas Manshur, Mohammad Natsir, KH. Hasyim Asyari, (Depok: Permata Artika Kreasi, 2001), hlm.37.

${ }^{3}$ Sudarsono, Opini: Ummat Islam Kedepankan Keteladanan, (Fajar: Jumat. 7 Desember 2007), hlm. 4.
} 
masyarakat indonesia membina persatuan bangsa. Dalam keberagaman itu terhimpun keinginan-keinginan yang ada menjadi hasrat kolektif dalam membangun dan memilihara keutuhan dan kesatuan bangsa dan negara. ${ }^{4}$

Keyakinan umat terhadap agamanya masing-masing tidak akan mengurangi rasa kebangsaaanya. Bahkan justru sebaliknya, memperkuat rasa kebangsaan dan cinta tanah air. Sebab setiap agama mewajibkan setiap pemeluknya dan mendorong penganutnya untuk membela kehormatan dan kedaulatan bangsa dan negaranya. Maka ungkapan cinta tanah air sebagian dari iman sangat berpengaruh dalam membangkitkan semngat bangsa indonesia khususnya umat islam .

Bagi umat islam, niat untuk menjadi satu adalah hal yang penting. Jika mencintai tanah air didasarkan kepada kebesaran dan keagungan tanah air di mana ia tinggal, maka dasarnya keyakinan itu telah menafikan eksistensi Tuhan. Sementara di dalam Islam setiap perilaku baik ibadah ataupun muamalah haruslah didasarkan kepada keyakinan terhadap Allah SWT. Hal itulah yang dikhawatirkan oleh kalangan Islam dengan cara merusak tauhid umat Islam dengan menekankan patriotisme dan pengorbanan untuk tanah air karena motivasi materialis (kebangsaan sempit). ${ }^{5}$

\section{Rumusan Masalah}

Dari latar belakang diatas, kami dapat mengambil rumusan masalah yang akan kami ulas, diantaranya yaitu :

1. Bagaimana hakikat paham kebangsaan (nasionalisme) dalam Islam?

2. Bagaimana wujud paham kebangsaan (nasionalisme) dalam Islam?

3. Apa tujuan paham kebangsaan (nasionalisme) dalam islam?

\section{Tujuan dan kegunaan Penulisan}

Adapun tujuan dari penulisan ini adalah untuk menemukan secara umum konsep paham kebangsaan. Penulisan ini akan menelusuri konsep tersebut secara tematik. Sedangkan kegunaan penulisan adalah untuk menambah pengetahuan tentang konsep yang dimaksud dan dapat menjadi bahan renungan dalam menumbuhkan semangat nasionalisme kita dalam hidup bermasyarakat.

\section{B. PEMBAHASAN}

\section{Hakikat Paham Kebangsaan (nasionalisme) dalam Islam}

Dalam perkembangan peradaban manusia, interaksi sesama manusia berubah menjadi bentuk yang lebih kompleks dan rumit. Dimulai dari tumbuhnya kesadaran untuk untuk menentukan nasib sendiri di kalangan bangsa-bangsa yang tertindas kolonialisme dunia, termasuk Indonesia, hingga melahirkan semangat untuk mandiri dan bebas menentukan masa depanya sendiri.

\section{4.}

${ }^{4}$ Habib Salim Barakwan, Opini: Tumbuhan Komiitmen Bersama, (Fajar: Jumat. 7 Desember 2007), hlm.

${ }^{5}$ Adhiyaksa Dault, Islam dan Nasionalisme, (Jakarta: Yadaul, 2003), hlm. 61. 
Dalam situasi perjuangan merebut kemerdekaan, dibutuhkan suatu konsep sebagai pembenaran rasional dari tuntutan terhadap penentuan nasib sendiri yang dapat mengikat keikutsertaan semua orang atas nama sebuah bangsa. Atas dasar pembenaran tersebut, selanjutnya mengkristal dalam konsep paham ideologi kebangsaan yang disebut dengan nasionalisme. ${ }^{6}$

Nasionalisme berasal dari kata nation yang dipadankan dengan bangsa.bangsa mempunyai dua pengertian, yaitu pengertian antropologis serta sosiologis, dan dalam pengertian politis. Dalam pengertian antropologis dan sosiologis, bangsa adalah suatu masyarakat yang merupakan suatu persekutuan hidup yang berdiri sendiri dan masing-masing anggota persekutuan hidup tersebut merasa satu kesatuan ras, bahasa, agama, sejarah, dan adat istiadat. ${ }^{7}$ Sedangkan yang dimaksud bangsa dalam pengertian politik adalah masyarakat dalam suatu daerah yang sama, dan mereka tunduk pada kedaulatan negaranya segabai suatu kekuasaan tertinggi. ${ }^{8}$

Rupert Emerson mendefinisikan nasionalisme sebagai komunitas orang-orang yang merasa bahwa mereka bersatu atas dasar elemen-elemen signifikan yang mendalam dari warisan bersama dan bahwa mereka memiliki takdir bersama menuju masa depan. Sedangkan menurut Ernest Renan, nasionalisme merupakan unsur yang dominan dalam kehidupan sisoal-politik sekelompok manusia dan telah mendorong terbentuknya suatu bangsa guna menyatukan kehendak untuk bersatu. Anggapan ini paralel dengan pandangan islam sebagaiman termaktub dalam Alquran surah Al-Hujurat, 49:13. ${ }^{9}$

Lebih lanjut dikalangan umat Islam dikenal sebuah pepatah yang berbunyi: hubbul wathani minal iman (cinta tanah air adalah bagian dari iman). Ini ditegaskan dalam Alquran yang menghendaki perubahan agar dilakukan oleh masyarakat. QS. 13:11:

"Sesungguhnya Allah tidak merobah keadaan sesuatu kaum sehingga mereka merobah keadaan yang ada pada diri mereka sendiri. ${ }^{10}$

Orang yang mengendalikan cinta tanah air itu termasuk dari pada iman, adalah hal yang tidak benar. Memang agama Islam tidak bertanah airtetapi kaum musliminnya yang bertanah air. Agama Islam tidak ada kebangsaan, tetapi kaum musliminnya berbangsa-bangsa menurut tempat dan daerahnya. ${ }^{11}$

B. Wujud Paham Kebangsaan (nasionalisme) dalam Islam

Islam mengakui perbedaan umat menurut afiliasi agama mereka. Orang-orang Kristen disebut segbagai ummat (komunitas) Yesus, orang-orang Yahudi disebut sebagai umat Musa, sebagaimana halnya kaum Muslim membentuk umat Nabi

${ }^{6}$ Dede Rosyada dkk, Pendidikan Kewargaan, Demokrasi, Hak Asasi Manusia dan Masyarakat Madani, (Jakarta: ICCE UIN Syarif Hidayatullah, 2003), hlm. 24.

${ }^{7}$ Badri Yatim, Soekarno, Islam dan Nasionalisme, (Jakarta: Logos Wacana Ilmu, 1999), hlm. 57-58.

${ }^{8}$ Badri Yatim, Soekarno, Islam dan Nasionalisme, (Jakarta: Logos Wacana Ilmu, 1999), hlm. 67.

${ }^{9}$ Anhiyaksa Dault, Op., Cit., hlm. 2.

${ }^{10}$ Anhiyaksa Dault, Op., Cit., hlm. 3.

${ }^{11}$ Dwi Purwoko dkk, Op., Cit., hlm. 37 
Muhammad. Ibrahim sendiri dinamakan sebagai umat yang patuh kepada Tuhan (QS. Al-Nahl 16:120), dan setiap umat memiliki satu perangkap ibadah yang dipilihkan oleh Allahuntuk mereka, Dan bagi tiap-tiap umat telah kami syariatkan suatu ibadah (QS. Al-Hajj 22:34). Pada awalnya hanya ada satu umat, manusia dahulunya adalah satu umat (QS. Yunus 10:19), tetapi seiring dengan perjalanan sejarah, berbagai macam umat terbentuk dan setelah itu banyak yang hilang atau hancur. Islam menggambarkan secara detail istilah muncul, hilang, dan kejatuhan berbagai umat, yang biasa disebut sebagai bangsa-bangsa. Kenyataanya, Tiap-tiap umat mempunyai batas waktu, maka apabila telah datang waktunya, mereka tidak dapat mengundurkanya barang sesaat pun dan tidak (dapat) pulamemajukannya (QS. Al-A'raf 7:34). ${ }^{12}$

Menurut Islam, umat (komunitas), makna dasarnya adalah suatu kolektivitas atau kumpulan manusia yang mereka semuua disatukan oleh tali agama, dan agama di dalamnyya berfungsi sebagai fondasi bagi hubungan sosial, hukum, politik, ekonomi, dan etika di antara anggota-anggotanya. Dalam periode sejarah, tidak hanya ada satu, tetapi banyak umat atau bangsa, yang artinya banyak agama, dan ini diterangkan dalam Alquran sebagai kondisi yang diinginkan oleh Tuhan, karena, Dan kalau Allah menghendaki, niscaya Allah menjadikan mereka satu umat saja (QS. AlSyura 42:8). Dalam konteks dunia dengan umat yang beragam inilah, yang semua dipandang Islam dalam kerangka religius, konsepsi Islam tentang dirinya sebagai satu ummat harus diletakan dan dipahami. ${ }^{13}$

Mengaitkan Islam dengan kebangsaan dapat dijelaskan dalam dua perspektif. Pertama, dari prespektif pluralisme dalam persatuan, Islam dan nasionalisme mempunyai hubungan positif. Islam mempunyai pengalaman panjang dan bahkan pioneer terbentuknya nasionalisme yang melahirkan negara bangsa. Negara madinah yang didirikan Nabi Muhammad adalah negara bangsa pertama di dunia. Kedua, dari perspektif uneversalisme, menurut Mansur, kebangsaan bertentangan dengan Islam. Sebagai agama universal, Islam tidak membatasi peruntukan bagi wilayah geografis dan etnis tertentu. Namun demikian, Islam tidak menafikan kenyataan bahwa setiap orang mempunyai afiliasi terhadap tanah air tertentu. Maka pepatah yang mengatakan "cinta tanah air sebagian dari iman", seperti dikataakan sebelumnya, sangat mempengaruhi pandangan kaum muslimin pada umumnya. Maka benarkah Mansur bahwa memang Islam tidak bertanah air, tetapi kaum musliminnya bertanah air. Dan umat Islam berkewajiban menjaga, mencintai, dan membela tanah airnya. ${ }^{14}$

Realitas kebangsaan dalam tubuh umat Islam merupakan implementasi dari

12 Seyyed Hossein Nasr, The Heart Of Islam: Pesan-pesan Universal Islam Untuk Kemanusiaan, diterjemahkan oleh Nurasiah Fakih Sutan Harahap dengan judul, The Heart Of Islam: Enduring Value For Humanity, (Bandung: Mizan, 2003), hlm. 192.

13 Seyyed Hossein Nasr, The Heart Of Islam: Pesan-pesan Universal Islam Untuk Kemanusiaan, diterjemahkan oleh Nurasiah Fakih Sutan Harahap dengan judul, The Heart Of Islam: Enduring Value For Humanity, (Bandung: Mizan, 2003), hlm. 193.

${ }^{14}$ Dwi Purwoko dkk, Op., Cit., hlm.37-38. 
misi "rahmatan lil alamin" sehingga eksklusifitas mereka harus diminimalkan. Sikap kebangsaan bagi mereka juga cermin dari faham monotheis yang menjadi fundamental keyakinannya, dimana semua realitas itu- termasuk eksklusifitas dan individualitas- haruslah dinegasikan dan hanya Allah yang menjadi esensi sesungguhnya, "la ilaha illallah". Norma tersebut kemudian diaplikasikan oleh Rasulullah SAW. Dalam membangun masyarakat Madinah di bawah panji "Piagam Madinah". Dalam perjanjian luhur yang mengikat Yahudi, Kristen, Muslim dan Paganis tersebut kata Islam dan Alquran sama sekali tidak pernah ditampilkan. Karakter ini diperkuat dengan risalah terakhir dalam Islam yang disampaikan Nabi saw. Dalam Haji Wada'. Dalam satu-satunya ibadah haji yang pernah dilakukan Rasulullah semasa hidup tersebut, beliau berpesan kepada seluruh umat manusia untuk selalu menghormati kehormatan dan hak-hak seseorang, mengangkat kehormatan wanita, menghindarkan pertumpahan darah dan seterusnya. ${ }^{15}$

\section{Tujuan Paham Kebangsaan (nasionalisme) dalam Islam}

Untuk melihat tujuan nasionalisme, maka perlu diperhatiakan konsep-konsep yang mendasari paham kebangsaan tersebut. Konsep-konsep yang dimaksud di antaranya adalah; unsur kesatuan/ persatuan, asal keturunan, bahasa, adat istiadat, sejarah, dan cinta tanah air.

Tidak dapat dipungkiri bahwa Islam menyerukan persatuan dan kesatuan. Seperti dijelaskan dalam QS. Al-Anbiya 21 dan Al-Mu'minn 23:52. "sesungguhnya umatmu ini adalah umat yang satu". ${ }^{16}$

Semangat nasionalisme merupakan semangat kelompok manusia yang hendak membangun suatu bangsa yang mandiri, dilandasi satu jiwa dan kesetiakawanan yang besar, mempunyai kehendak untuk bersatu dan terus menerus ditingkatkan untuk bersatu, dan menciptakan keadilan dan kebersamaan. Nasionalisme ini, misalnya membentuk persepsi dan konsepsi identitas sosial kaum pergerakan Indonesia sebagai suatu kekuatan politik yang tidak bisa dinegasikan oleh penguasa kolonial. Tjuan nasionalisme ini adalah pembebasan dari penjajahan dan menciptakan masyarakat/negara yang adil, dimana tidak ada lagi penindasan manusia oleh manusia. Sebagaimana dalam QS. Al-Baqarah 2:279

Terjemahannya:

"Kamu tidak menganiaya dan tidak (pula) dianiaya". ${ }^{17}$

Meskipun terdapat perbedaan pendapat tentang unsur "persamaan keturunan" dalam hal kebangsaan, bahkan dengan melihat kenyataan bahwa tidak ada satu bangsa yang hidup pada masa sekarang di mana seluruh anggota masyarakatnya berasal dari satu keturunan yang sama.

\footnotetext{
${ }^{15}$ Said Aqiel Siradj, Op., Cit., hlm. 193.

${ }^{16}$ M . Qurais Shihab, Op., Cit., hlm. 334.

${ }^{17}$ Adhiyaksa Dault, Op., Cit., hlm. 3.
} 
Alquran menegaskan bahwa Allah swt. Menciptakan manusia dari satu keturunan dan bersuku-sukuu (demikian juga rumpun dan ras manusia), agar mereka saling mengenal potensi masing-masing dan memanfaatkannya semaksimal mungkin. Ini mengisyaratkan bahwa Islam mendukung pengelompokan berdasarkan keturunan, selama tidak menimbulkan perpecahan. Hal ini dibenarkan dalam QS. Al-A'raf 7:160.

“160. Dan mereka kami bagi menjadi dua belas suku yang masing-masingnya berjumlah besar dan kami wahyukan kepada musa ketika kaumnya meminta air kepadanya:"Pukullah batu itu dengan tongkatmu!". Maka memancarlah dari padanya dua belas mata air..$^{18}$

Dalam hal bahasa- sebagai unsur kebangsaan- QS. Al-Rum 30:22 menegaskan sebagai berikut:

“Dan di antara tanda-tanda kekuasaan-Nya ialah menciptakan langit dan bumi dan berlain-lainan bahasamu dan warna kulitmu.

Alquran begitu menghargai bahasa dan keragamannya, hingga mengakui pemakaian bahasa lisan yang beragam. Dalam konteks paham kebangsaan, Alquran sangat menghormati bahasa, sebagaimana hadis Nabi Saw. ${ }^{19}$

"Alquran diturunkan, sebagaimana hadis bahasa".

Pada hakikatnya, bahasa memang bukan digunakan sekedar untuk menyampaikan tujuan pembicaraan dan yang diucapkan oleh lidah. Bahasa merupakan jembatan penyalur perasaan dan pikiran. ${ }^{20}$

Pikiran dan perasaan satu kelompok/umat tercermin antara lain dalam adat istiadatnya. Hal ini dinyatakan dalam QS. Ali-'Imran 3:104,

"Dan hendaklah ada di antara kamu segolongan umat yang menyeru kepada kebajikan ma'ruf dan mencegah dari yang munkar"

“199. Jadilah Engkau Pema'af dan suruhlah orang mengerjakan yang ma'ruf, serta berpalinglah dari pada orang-orang bodoh" ${ }^{21}$

Penjabaran kebaikan dapat beragam sebagaimana kondisi masyarakat. Sehingga memungkinkan satu masyarakat berbeda dengan masyarakat lain. Apabila penjabaran tersebut tidak bertentangan dengan prinsip ajaran agama, maka itulah yang disebut 'urf/ma'ruf. ${ }^{22}$

Para pakar hukum menetapkan bahwa adat kebiasaan dalam suatu kelompok masyarakat selama tidak bertentangan dengan prinsip ajaran Islam, maka dapat dijadikan sebagai salah satu pertimbangan hukum (al-adat muhakkimah). ${ }^{23}$

\footnotetext{
${ }^{18}$ M . Qurais Shihab, Op., Cit., hlm. 337.

${ }^{19}$ HR. Muslim, At-Tirmidzi, dan Ahmad dengan riwayat yang berbeda-beda tetapi dengan makna yang

${ }^{20}$ M . Qurais Shihab, Op., Cit., hlm. 340-341.

${ }^{21}$ QS. Al-A'raf 7:199.

${ }^{22}$ M . Qurais Shihab, Op., Cit., hlm. 343.

${ }^{23}$ M . Qurais Shihab, Op., Cit., hlm. 343.
} sama. 
Faktor persamaan sejarah menjadi unsur kebangsaan karena dianggap penting dalam rangka menyatukan perasaan, pikiran dan langkah masyarakat. Dengan melihat sejarah, umat, bangsa dan kelompok dapat belajar dari segi positif dan negatif pengalaman masa lampau untuk menapaki jalan menuju masa akan datang. Fakta sejarah yang cemerlang akan menjadi motivasi bagi anggota kelompok serta generasi selanjutnya.

Menurut Alquran, tujuan utama dari uraian sejarahnya adalah untuk mengambil pelajaran, guna menetapkan langkah selanjutnya. Unsur kesejarahan sejalan dengan ajaran Islam, selama kesejarahan itu diarahkan itu diarahkan guna mencapai kebaikan dan kemaslahatan. ${ }^{24}$

Selanjutnya unsur cinta tanah air (patriotisme) merupakan pembuktian rasa kebangsaan. Sudah menjadi tabiat manusia, mencintai negeri tempat ia dilahirkan. Bahkan kemanapu ia pergi, rasa ingin kembali ke tanah air senantiasa muncul. ${ }^{25}$

Ketika Rasulullah SAW. Berhijrah ke Madinah, beliau sholat menghadap ke Bait Al-Maqdis. Tetapi, setelah enam belas bulan, rupanya beliau rindu kepada Makkah dan ka'bah, karena merupakan kiblat leluhurnya dan kebangsaan orangorang Arab. Wajah beliau bolak-balik menengadah ke langit, bermohon agar kiblat diarahkan ke Mekkah. ${ }^{26}$, maka Allah merestui dengan turunya ayat:

Sungguh kami (sering) melihat mukamu mengadah ke langit, Maka sungguh kami akan memalingkan kamu ke Kiblat yang kamu sukai. Palinkanlah mukamu ke arah Masjidil Haram. Dan dimana saja kamu berada, palingkanlah mukamu arahnya. Dan sesungguhnya orang-orang (Yahudi dan Nasrani) yang diberi Al Kitab (Taurat dan Injil) Haram itu adalah benar dari Tuhannya; dan Allah sekali-kali tidak lengah dari apa yang mereka kerjakan. ${ }^{27}$

Khusus mengenai tanah air, Natsir pernah menulis dalam artikel:

“Dan janganlah lupa, bahwa tanah airnya sendiri itu sebahagian dari tanah air agamanya, dan wajib ia sungguh-sungguh untuk menjadikan kemajuan tanah airnya sebagai wasilah untuk kemajuan dunia Islam".

Natsir berpandangan, merupakan suatu keharusan dalam perjuangan pembentukan sebuah negara bangsa. Paham kebangsaan merupakan sebuah alat yang perlu untuk merealisasikan ajaran-ajaran Islam ke dalam situasi yang kongkrit. ${ }^{28}$

\section{KESIMPULAN}

Dari uraian di atas mengenai konsepsi paham kebangsaan dalam Islam, maka dapat diambil beberapa kesimpulan sebagai berikut:

\footnotetext{
${ }^{24}$ M . Qurais Shihab, Op., Cit., hlm. 343.

${ }^{25}$ M. Natsir, Agama dan Negara Dalam Perspektif Islam, (Jakarta: Media Da'wah, 2001), hlm. 46.

${ }^{26}$ M . Qurais Shihab, Op., Cit., hlm. 348

${ }^{27}$ QS. Al-Baqrah 2:144.

${ }^{28}$ Dwi Purwoko dkk, Op., Cit., hlm. 77.
} 
1. Nasionalisme dapat dikatakan sebagai sebuah situasi kejiwaan di mana kesetian seseorang secara total diabadiakan langsung kepada negara, di mana masyarakatnya dipersatukan karena ras, bahasa, agama, sejarah dan adat. Hal tersebut berdasar pada penciptaan manusia yang terdiri atas laki-laki dan perempuan, bersuku-suku dan berbangsa-bangsa.

Nasionalisme merupakan semangat kelompok manusia yang hendak membangun suatu bangsa yang mandiri, dilandasi satu jiwa dan kesetiakawanan yang besar.

2. Mencintai tanah air tidak dilarang agama. Yang dilarang adalah mengurus suatu negara atau mengajak orang lain untuk mengurusnya dengan asa kebangsaan tanpa mengambil atura Islam. Semangat nasionalisme serta cinta tanah air dan menyatukannya dengan aturan islam adalah sikap terpuji.

Sebagaimana Alquran surah Al-Hujurat mengakui eksistensi bangsa-bangsa, tapi menolak nasionalisme sempit yang mengarah kepada Ashabiyah. Kebangsaan adalah suatu fitrah dan alamiyah.

3. Dengan adanya semangat nasionalisme yang berdasarkan atas persamaan niat dan tujuan untuk bersatu dan hendak membangun bangsanya menuju masa depan. Dengan penciptaan manusia yang bersuku-suku dan berbangsa-bangsa tidak lain untuk saling kenal mengenal sehingga tercipta kebersamaan dan keharmonisan dalam kehidupan berbangsa dan bermasyarakat.

\section{Daftar Pustaka}

Baqi, Muhammad Fuad Abdul. Al-Mu'jam Al-Mufahras Li Al-Faz Al-Quran AlKarim, Beirut: Dar al Fikri. 1987

Barakwan, Habib Salim. Opini: Tumbuuhkan komitmen Bersama, Fajar: Jumat. 7 Desember. 2007

Dault, Adhiyaksa. Islam dan Nasionalisme, Jakarta:Yadaulu.2003

Dwi Purwoko dkk. Negara Islam, Percikan Pemikiran: H. Agus Salim, KH. Mas Manshur, Mohammad Natsir, KH. Hasyim Asyari, Depok: Permata Atika Kreasi. 2001

John J. Donohue dan John L. Esposito. Islam dan Pembaharuan: Ensiklopedia Masala-masalah diterjemahkan dari buku aslinya yang berjudul, Islam and Tradition: Muslim Perspectives, Jakarta: Raja Grafindo Persada. 1994

M.Natsir, Agama dan Negara Dalam Prespektif Islam, Jakarta: Media Da'wah. 2001

Nasr, Seyyed Hossein. The Heart Of Islam: Pesan-pesan Universal Islam Untuk Kemanusian, diterjemahkan oleh Nurasiah Fakih Sutan Harahap dengan judul, The Heart Of Islam: Enduring Value For Humanity, Bandung: Mizan. 2003 
Rosyada, Dede, dkk. Pendidkan Kewargaan, Demokrasi, Hak Asasi Manusia dan Masyarakat Madani, Jakarta: ICCE UIN Syarif Hidayatullah. 2003

Shihab, M.Qurais. Wawasan Alquran, Tafsir Maudhu'i atas Pelbagai Persoalan Umat, Bandung: Mizan. 1996

Siradj, Said Aqiel. Islam Kebangsaan, Fiqih Demokratik Kaum Santri, Jakarta: Pustaka Cinganjur.1999

Sudarsono, Opini.Umat Islam Kedepankan Keteladanan, Fajar:Jumat. 7 Desember.2007

Tim Penyususun Kamus Pusat Pembinaan dan Pengembangan Bahasa. Kamus Besar Indonesia, ed. II, cet. III, Jakarta: Balai Pustaka. 1994

Yatim, Badri. Soekarno, Islam dan Nasionalisme, Jakarta: Logos Wacana Ilmu. 1999 